Annals of Pure and Applied Mathematics

Vol. 16, No. 1, 2018, 63-67

ISSN: 2279-087X (P), 2279-0888(online)

Published on 1 January 2018

www.researchmathsci.org

DOI: http://dx.doi.org/10.22457/apam.v16n1a8

Annals of

Pure and Applied

Mathematics

\title{
R Index of Some Graphs
}

\author{
A. Sumathi \\ Department of Mathematics, Seethalakshmi Ramaswami College \\ Tiruchirappalli, Tamil Nadu, India. E-mail: suma_shivasrc@yahoo.com \\ Received 30 November 2017; accepted 13 December 2017
}

\begin{abstract}
A topological representation of a molecule is called molecular graph. A molecular graph is a collection of points representing the atoms in the molecule and set of lines representing the covalent bonds. These points are named vertices and the lines are named edges in molecular graph theory. In this paper, the expression of the new $\mathrm{R}$ index of path graph, star graph, wheel graph, gear graph, helm graph are derived.
\end{abstract}

Keywords: Degree of vertex, Neighbourhood, Topological indices

AMS Mathematics Subject Classification (2010): 05CXX, 94C15

\section{Introduction}

A topological index is a numerical invariant that characterize the chemical properties of a molecule. The Wiener index $\mathbf{W}(\mathbf{G})$ is a distance-based topological invariant much used in the study of the structure-property and the structure-activity relationships of various classes of biochemically interesting compounds, which is introduced by Harold Wiener in 1947 for predicting boiling points b. p of alkanes based on the formula $b . p=\alpha W+\beta w(3)+\gamma$, where $\alpha, \beta, \gamma$ are empirical constants, and $\mathrm{w}(3)$ is called path number. It is defined as the half sum of the distances between all pairs of vertices of G. $W(G)=\frac{1}{2} \sum_{u, v \in G} d(u, v)$, where $\mathrm{d}(\mathrm{u}, \mathrm{v})$ is the number of edges in a shortest path that connecting the vertices $\mathrm{u} \& \mathrm{v}$ in $\mathrm{G}[13,20]$. As of now, innumerable "Molecular descriptors" are being proposed. Recently, degree based topological indices are also made a good correlation with chemical properties of a molecule. Some well-known degree based topological indices are Randic index, First and Second Zagreb indices, Reformulated first and second Zagreb indices, Atom-Bond Connectivity index, Augmented Zagreb index, Harmonic index, Geometric-arithmetic index, Sumconnectivity index, etc.[1,2,4-10,12,14-17,19,20]. The comparative testing of these wellknown degrees based topological indices were given in [11]. The concept of $\mathrm{R}$ degree of a vertex and $\mathrm{R}$ index of a graph were introduced by Siileyman Ediz and computed the $\mathrm{R}$ degree of a vertex and $R$ index of some well-known graphs in [18]. Throughout this paper only simple connected graphs was considered, i.e. connected graphs without self-loops and parallel edges. 


\section{A. Sumathi}

\section{Definitions}

For a graph $G, V(G)$ and $E(G)$ denote the set of all vertices and edges respectively. The degree of the vertex $\mathrm{v}$ is defined as the number of edges incident with $\mathrm{v}$ and denoted by $\mathrm{d}(\mathrm{v})$. The set of all vertices which are adjacent to $\mathrm{v}$ is called the neighborhood of $\mathrm{v}$ and denoted by $\mathrm{N}(\mathrm{v})$. For a vertex $\mathrm{v}$, the sum degree of $\mathrm{v}$ is defined as $S_{v}=\sum_{u \in N(v)} \operatorname{deg}(u)$ and for a vertex $\mathrm{v}$, the multiplication degree of $\mathrm{v}$ is defined as $M_{v}=\prod_{u \in N(v)} \operatorname{deg}(u)$.The $\mathrm{R}$ degree of a vertex $\mathrm{v}$ of a simple connected graph $\mathrm{G}$ is defined as $r(v)=S_{v}+M_{v}$. The first $\mathrm{R}$ index of a simple connected graph $\mathrm{G}$ defined as $R^{1}(G)=\sum_{v \in G}(r(v))^{2}$. The Second $\mathrm{R}$ index of a simple connected graph $\mathrm{G}$ defined as $R^{2}(G)=\sum_{u v \in E} r(u) r(v)$. The Third $\mathrm{R}$ index of a simple connected graph $\mathrm{G}$ defined as $R^{3}(G)=\sum_{u v \in E}[r(u)+r(v)]$

Our notation is standard and mainly taken from standard books of graph theory [3]

\section{3. $\mathbf{R}$ index of some graphs}

Theorem 3.1. Let $P_{n}$ be the path graph with n vertices $(n \geq 3)$ then

$$
\begin{aligned}
& R^{1}\left(P_{n}\right)=64 n-174 \\
& R^{2}\left(P_{n}\right)=64 n-200 \\
& R^{3}\left(P_{n}\right)=16 n-4
\end{aligned}
$$

Proof: Let $P_{n}$ be the Path graph with n vertices and n-1 edges . ie. $\left|V\left(P_{n}\right)\right|=n$ and $\left|E\left(P_{n}\right)\right|=n-1$ For the Pendent vertices $v_{1}$ and $v_{n}, S_{v_{1}}=S_{v_{n}}=2=M_{v_{1}}=M_{v_{n}}=2$ and for the vertices $v_{2}, v_{n-1}, S_{v_{2}}=S_{v_{n-1}}=3$ and $M_{v_{2}}=M_{v_{n-1}}=2$.For the rest of the internal vertices $S_{v_{3}}=\ldots=S_{v_{n-2}}=M_{v_{3}}=\ldots=M_{v_{n-2}}=4$.

Hence, $r\left(v_{2}\right)=r\left(v_{n-1}\right)=5, r\left(v_{3}\right)=\ldots=r\left(v_{n-2}\right)=8$

After Simplification,

$$
\begin{aligned}
& R^{1}\left(P_{n}\right)=2.4^{2}+2.5^{2}+(n-4) 8^{2}=64 n-174 \\
& R^{2}\left(P_{n}\right)=2.5 .8+2.4 .5+65(n-5)=64 n-200 \\
& R^{3}\left(P_{n}\right)=2.4 .5+2(5+8)+16(n-5)=16 n-4
\end{aligned}
$$

Theorem 3.2. Let $S_{n}$ be the Star graph with $n$ vertices $(n \geq 3)$ then

$$
\begin{aligned}
& R^{1}\left(S_{n}\right)=n^{2}+4(n-1)^{3} \\
& R^{2}\left(S_{n}\right)=2 n(n-1)^{2} \\
& R^{3}\left(S_{n}\right)=(n-1)(3 n-2)
\end{aligned}
$$




\section{R Index of Some Graphs}

Proof: Let $S_{n}$ be the Star graph with n vertices and n-1 edges . ie. $\left|V\left(S_{n}\right)\right|=n$ and $\left|E\left(S_{n}\right)\right|=n-1$

For the Pendent vertices $v_{1}, \ldots, v_{n-1}, S_{v_{1}}=\ldots=S_{v_{n-1}}=n-1=M_{v_{1}}=\ldots=M_{v_{n-1}}$ and for the central vertex $v_{n}, S_{v_{n}}=n-1$ and $M_{v_{n}}=1$.

Hence $r\left(v_{1}\right)=\ldots=r\left(v_{n-1}\right)=2 n-2, r\left(v_{n}\right)=n$

After Simplification,

$$
\begin{aligned}
& R^{1}\left(S_{n}\right)=(n-1)(2 n-2)^{2}+n^{2}=4(n-1)^{3}+n^{2} \\
& R^{2}\left(S_{n}\right)=n(n-1)(2 n-2)=2 n(n-1)^{2} \\
& R^{3}\left(S_{n}\right)=(n-1)(2 n-2+n)=(n-1)(3 n-2)
\end{aligned}
$$

Theorem 3.3. Let $W_{n}$ be the Wheel graph with $n$ vertices $(n \geq 4)$ then

$$
\begin{aligned}
& R^{1}\left(W_{n}\right)=(n-1)(10 n-4)^{2}+\left(3(n-1)+3^{n-1}\right)^{2} \\
& R^{2}\left(W_{n}\right)=(n-1)(10 n-4)\left(13 n-7+3^{n-1}\right) \\
& R^{3}\left(W_{n}\right)=3(n-1)\left(11 n-5+3^{n-2}\right)
\end{aligned}
$$

Proof: Let $W_{n}$ be the Wheel graph with $\mathrm{n}$ vertices and $2 \mathrm{n}-2$ edges is obtained by connecting a single vertex to a vertices of a cycle of length n-1

ie. $\left|V\left(W_{n}\right)\right|=n$ and $\left|E\left(W_{n}\right)\right|=2 n-2$

For the vertices $v_{1}, \ldots, v_{n-1}, S_{v_{1}}=\ldots=S_{v_{n-1}}=5+n, \quad M_{v_{1}}=\ldots=M_{v_{n-1}}=9(n-1)$ and for the central vertex $v_{n}, S_{v_{n}}=3(n-1)$ and $M_{v_{n}}=3^{n-1}$.

Hence $r\left(v_{1}\right)=\ldots=r\left(v_{n-1}\right)=5+n+9(n-1), r\left(v_{n}\right)=3(n-1)+3^{n-1}$

After Simplification,

$$
\begin{aligned}
& R^{1}\left(W_{n}\right)=(n-1)(10 n-4)^{2}+\left(3(n-1)+3^{n-1}\right)^{2} \\
& R^{2}\left(W_{n}\right)=(n-1)(10 n-4)\left(13 n-7+3^{n-1}\right) \\
& R^{3}\left(W_{n}\right)=3(n-1)\left(11 n-5+3^{n-2}\right)
\end{aligned}
$$

Theorem 3.4. Let $H_{n}$ be the Helm graph with $2 \mathrm{n}-1$ vertices $n \geq 4$ then

$$
\begin{aligned}
& R^{1}\left(H_{n}\right)=(n-1)(17 n-8)^{2}+\left(4(n-1)+4^{n-1}\right)^{2}+64(n-1) \\
& R^{2}\left(H_{n}\right)=(n-1)(17 n-8)\left(21 n-4+4^{n-1}\right) \\
& R^{3}\left(H_{n}\right)=4(n-1)\left(18 n-7+4^{n-2}\right)
\end{aligned}
$$

Proof: Let $H_{n}$ be the Helm graph with 2n-1 vertices and 3n-3 edges is obtained from the Wheel $W_{n}$ by adding a pendent edge at each vertex on the rim of $W_{n}$ ie. $\left|V\left(H_{n}\right)\right|=2 n-1$ and $\left|E\left(H_{n}\right)\right|=3 n-3$ 
A. Sumathi

For the vertices $v_{1}, \ldots, v_{n-1}$, in $C_{n-1}, S_{v_{1}}=\ldots=S_{v_{n-1}}=8+n$,

$M_{v_{1}}=\ldots=M_{v_{n-1}}=16(n-1)$ and for the central vertex $v_{n}, S_{v_{n}}=4(n-1)$ and

$M_{v_{n}}=4^{n-1}$. For the Pendent vertices, $S_{v}=4$ and $M_{v}=4$.

Hence $r\left(v_{1}\right)=\ldots=r\left(v_{n-1}\right)=17 n-8, r\left(v_{n}\right)=4(n-1)+4^{n-1}, r\left(v_{n+1}\right)=\ldots r\left(v_{2 n-1}\right)=8$

After Simplification,

$$
\begin{aligned}
& R^{1}\left(H_{n}\right)=(n-1)(17 n-8)^{2}+\left(4(n-1)+4^{n-1}\right)^{2}+64(n-1) \\
& R^{2}\left(H_{n}\right)=(n-1)(17 n-8)\left(21 n-4+4^{n-1}\right) \\
& R^{3}\left(H_{n}\right)=4(n-1)\left(18 n-7+4^{n-2}\right)
\end{aligned}
$$

Theorem 3.5. Let $G_{n}$ be the Helm graph with $2 \mathrm{n}+1$ vertices $n \geq 4$ then

$$
\begin{aligned}
& R^{1}\left(G_{n}\right)=(n-1)(5 n-1)^{2}+\left(3(n-1)+3^{n-1}\right)^{2}+225(n-1) \\
& R^{2}\left(G_{n}\right)=3(n-1)(5 n-1)\left(3^{n-2}+n+9\right) \\
& R^{3}\left(G_{n}\right)=3(n-1)\left(3^{n-2}+6 n+8\right)
\end{aligned}
$$

Proof: Let $G_{n}$ be the Gear graph with $2 \mathrm{n}+1$ vertices and 3 n edges is obtained by inserting an vertex between each pair of adjacent vertices on the rim of a Wheel $W_{n}$.

ie. $\left|V\left(G_{n}\right)\right|=2 n+1$ and $\left|E\left(G_{n}\right)\right|=3 n$

For the vertices $v_{1}, \ldots, v_{n-1}$, in $C_{n-1}, S_{v_{1}}=\ldots=S_{v_{n-1}}=3+n$,

$M_{v_{1}}=\ldots=M_{v_{n-1}}=4(n-1)$ and for the central vertex $v_{n}, S_{v_{n}}=3(n-1)$ and

$M_{v_{n}}=3^{n-1}$. For the inserting vertices, $S_{v}=6$ and $M_{v}=9$.

Hence $r\left(v_{1}\right)=\ldots=r\left(v_{n-1}\right)=5 n-1, r\left(v_{n}\right)=3(n-1)+3^{n-1}, r\left(v_{n+1}\right)=\ldots r\left(v_{2 n+1}\right)=15$

After Simplification,

$$
\begin{aligned}
& R^{1}\left(G_{n}\right)=(n-1)(5 n-1)^{2}+\left(3(n-1)+3^{n-1}\right)^{2}+225(n-1) \\
& R^{2}\left(G_{n}\right)=3(n-1)(5 n-1)\left(3^{n-2}+n+9\right) \\
& R^{3}\left(G_{n}\right)=3(n-1)\left(3^{n-2}+6 n+8\right)
\end{aligned}
$$

\section{Conclusion}

In this paper, the expression of the new R index of Path graph, Star Graph, Wheel graph, Gear graph, Helm graph are derived.

\section{REFERENCES}

1. B.Zhou and N.Trinajstić, On a novel connectivity index, J. Math. Chem., 46 (2009) 1252-1270.

2. B.S.Durgia, S.M.Mekkalikeb, H.S.Ramane, On the Zagreb indices of semi total point graphs of some graphs handed, Annals of Pure and Applied Mathematics, 12(1) (2016) 49-57. 


\section{R Index of Some Graphs}

3. R.Balakrishnan and K.Renganathan, A Text Book of Graph Theory, Springer Verlag, New York, (2000)

4. D.Vukičević and B.Furtula, Topological index based on the ratios of geometrical and arithmetical means of end-vertex degrees of edges, J. Math. Chem., 46 (2009) 1369-1376.

5. K.C.Das, K.Xu and J.Nam, On Zagreb indices of graphs, Front. Math. China, 10 (2015) 562-582.

6. E.Estrada, L.Torres, L.Rodríguez and I.Gutman, Indian J. Chem., 37A (1998) 849.

7. I.Gutman and N.Trinajstic, Graph theory and molecular orbitals, Total pi-Electron Energy of Alternant Hydrocarbons, Chemical Physics Letters, 17 (1972) 535-538

8. I.Gutman, B. Ruščić, N.Trinajstić, C.N.Wilcox, Graph theory and molecular orbitals XII, Acyclic Polyenes, J.Chem. Phys., 62 (1975) 3399-3405.

9. I.Gutman, N.Trinajstić, Graph theory and molecular orbitals. XV. The Huckle rule, The Journal of Chemical Physics, 64 (1976) 4921.

10. Ilić .A, Note on the harmonic index of a graph, Ars Combin., 128 (2016) 295-299.

11. Ivan Gutman, Degree-Based topological indices, Croat. Chem. Acta, 86 (4) (2013) 351-361.

12. J.Li, J.B.Lv and Y.Liu, The harmonic index of some graphs, Bull. Malays. Math. Sci. Soc., 39 (2016) 331-340.

13. K.Thilakam and A.Sumathi, Wiener index of a cycle in the context of some graph operations, Annals of Pure and Applied Mathematics, 5 (2) (2014) 183-191.

14. L.Zhong, The harmonic index for graphs, Applied Mathematics Letters, 25 (2012) 561-566.

15. L.Zhong, The harmonic index on unicyclic graphs, Ars Combin., 104 (2012) 261269.

16. M.Randić, Characterization of molecular branching, J. Am. Chem. Soc., 97 (1975) 6609-6615.

17. A.Milicevic, S.Niiolic and N.Trinajstic, On reformulated Zagreb indices, Mo.. Divers..8 (2000) 393-399.

18. E.Siileyman, On $\mathrm{R}$ degrees of vertices and $\mathrm{R}$ indices of graphs, International Journal of Advanced Chemistry, 5(2) (2017) 70-72.

19. W.Gao, L.Liang and Y.Chen, On second geometric-arithmetic index and co-pi index of special chemical molecular structures, Annals of Pure and Applied Mathematics, 13(1) (2017) 99-117.

20. H.Wiener, Structural determination of paraffin boiling points, J. Am Chem. Soc., 6 (1947) 17-20. 